\title{
Postface: Meaning of the Experiment and Implications of the Experience
}

\author{
Frederic Le Marcis, PhD
}

\begin{abstract}
Discussing specifically on the involvement of social sciences in and on the issue of recruitment in HIV vaccine trials, the postface of this special issue reasserts the importance of social science engagement in clinical research. Three entry themes are underlying the discussion: the relationship between the individual and society in consent, the analysis of consent as a transaction, the examination of the basis, and the context of trust within trials.
\end{abstract}

Key Words: postface, inclusion, vaccine trials, Global South, HIV

(J Acquir Immune Defic Syndr 2018;79:S69-S73)

$\mathrm{T}_{\mathrm{H}}^{\mathrm{h}}$ he website ClinicalTrials.gov of the National Institutes of Health (NIH) in the United States has a database on all the clinical trials that have taken place or are taking place in the world. When consulted as to HIV vaccine trials (viewed on August 16, 2017, https://clinicaltrials.gov) [Du recrutement à l'engagement dans la recherche: interactions et médiations constitutives des recherches en prévention contre le $\mathrm{VIH}$ au Nord ("Recruitment for engagement in research: interactions and mediations in research on the prevention of HIV in Nord"), a study day organized by Mathilde Couderc and Caroline Ollivier-Yaniv, June 12, 2015, Université Paris-Est Créteil], it showed that 336 trials concerning a vaccine and HIV/AIDS were conducted in early phase 1 or phase 1 . At the time of writing, 47 trials were soon to start recruitment, in the process of recruitment, or simply in progress with recruitment closed. In addition to these trials are trials concerning preexposure treatment (383 trials in total). All are part of a common effort driven in the hope of eradicating HIV.

The geographical and temporal scope of these trials gives cause to consider the conditions, basis, and practice of consent and recruitment. These considerations are irrelevant beyond the topic of HIV, but it should be noted that it is highly relevant for the very topical question of hemorrhagic fevers for which the vaccine currently seems to be the most promising answer. To understand the question of recruitment

From the Département des sciences sociales Research Team LADEC (FRE 2002, CNRS, Lyon 2, ENS-L), Ecole Normale Supérieure de Lyon (ENS-L), Lyon, France.

Presented in part at "Recruitment and engagement in preventive trials" conference; June 12, 2015 by C. Ollivier-Yaniv and M. Couderc for the Vaccine Research Institute (VRI) at Université Paris-Est Créteil; Créteil, France.

The authors have no funding or conflicts of interest to disclose.

Correspondence to: Frederic Le Marcis, PhD, ENS de Lyon, 15 parvis René

Descartes, 69007 Lyon, France (e-mail: frederic.lemarcis@ens-lyon.fr).

Copyright (C) 2018 Wolters Kluwer Health, Inc. All rights reserved. and consent, this work, which is the product of a meeting organized by the Vaccine Research Institute, goes beyond a strictly bioethical approach and examines the more general social motivations which determine participation in vaccine trials such as interessement (this is a sociological notion translated as such in English), ${ }^{1}$ ie, the way in which researchers, caregivers, and volunteers but also the virus, vaccine, parents, and/or loved ones of volunteers contribute to the joint production of research on the capacity of a candidate vaccine to generate immunity from HIV. The special issue reminds us that, to produce this knowledge, an evaluation of the safety of the candidate vaccine is initially required, ie, a phase 1 trial. This involves a four-step process (the 4 phases of the clinical trial, cf. the chapter of C. Durier et al in this special issue). The aim in this case is not to evaluate the efficacy of a product but its safety in healthy subjects.

I identify 4 avenues from my reading of this rich and stimulating work. The first concerns the relationship between the individual and society in consent. From the first flows the second, which consists of deepening an analysis of consent as a transaction. The third concerns an examination of the basis and context of trust within trials. Finally, the diversity of opinion in the social sciences with regard to trials, as shown by the contributions, makes it possible to resume the discussion of the role of the social sciences in recruitment, somewhere between analysis and active participation.

\section{THE VOLUNTEER, CONSENT, AND SOCIETY}

Regarding a trial concerning the early treatment of HIV and tuberculosis, Brives ${ }^{2}$ describes in great ethnographic detail the different sequences which structure the execution of a clinical trial and the way in which they lead to the individual "becoming an object." She emphasizes the fact that the process of "becoming an object" is probably more accurately expressed by the notion of multiple trajectories borrowed from Bowker and $\mathrm{Star}^{3}$ (Brives uses the notion of "multiple trajectories" 3 to consider the interaction of various facets of the individual in a therapeutic trial.), but her description also goes beyond the concept of the trial as a series of predefined stages and envisages it as a process which is renegotiated during every interaction. The various experiences described in this special issue also describe recruitment and consent as a negotiation or an agreement which is constantly renewed during interactions between the various participants in the trial. In fact, consent is not limited to the signing of a form but extends over a much longer period of time. Every visit of the volunteer is a new manifestation of his or her consent. 
Participation in a therapeutic trial may thus be seen in this light as a reiteration "by the body" of the consent to play the role of the subject in a trial.

Behind the public script of recruitment (altruism, science) is an infra-political script ${ }^{4,5}$ [With the notion of the infra-political script, Scott intends to analyze how, beyond visible forms of domination and rebellion, the dominated develop practices and forms of engagement which are derived from alternative moral universes, which characterize their lives $\left(\mathrm{cf}^{5}\right)$.] which covers the spectrum of negotiations and interests involved. ${ }^{1}$ By seeing recruitment in this way, the authors embrace the different bases which structure it, as well as the multiple trajectories which cut through it. This goes beyond the dualist view that sees recruitment as a reproduction of the doctor-patient dichotomy. Instead, recruitment is understood as an interaction involving multiple contributors. These contributors are involved in the trial itself (researchers, clinicians, monitors and clinical study technicians, drivers, etc.) but also include the volunteers (parents, partners, and social network) and the technologies used in the trial. The situations reported in this article remind us that we cannot understand the basis for the engagement (or nonengagement) of volunteers without considering the way in which their participation in a trial is perceived, assessed, and negotiated within their social networks (cf. the chapter by C. Durier et al, in this special issue). These situations also invite consideration of how the volunteer's relationship to his or her body and the risk mediated by technology in a trial transforms the volunteer's experience of the world.

In this regard, the discussion of the notion of the individual based on sites and clinical trial experiments in nonWestern contexts is highly illuminating. ${ }^{6}$ For the Sri Lankan clinicians interviewed by Sariola and Simpson and involved in either clinical trials or bioethical analysis, the application of the principles of bioethics involving the manifestation of the free and informed consent of the individual, who is conceived of as an autonomous entity, does violence to the impossibility for the contributors (Sri Lankan clinicians and volunteers) of seeing the individual outside the group to which he or she belongs. By taking part in a trial, the individual effectively also involves his kin and must therefore obtain their consent. Melissa Graboyes also shows how during the colonial period in East Africa, the trials conducted for malaria relied on consent obtained for the entire population solely from traditional chiefs.

Whether the community imposes itself as a given to be taken into account in the negotiation of recruitment, as in Sri Lanka, or whether it appears, on the contrary, to be a means to justify nonconsultation of the individual in consent, as in East Africa, in all the cases, the notion of community imposes an enhanced conception of the individual. In the examples reported for the Western cases, the withdrawal of some participants and the fears expressed a posteriori (regarding the impact of the trial on a relationship or social life) show the return of the social in a consent which is purported to be an individual decision. In this context, the experience of induced seropositivity (or the fear of this experience) must not be seen as an incomprehension of the mechanism of vaccination or the functioning of antibodies, but indeed as the product of an

S70 | www.jaids.com identity produced within the framework of the interaction between the individual and the trial and appreciated in the light of the social (cf. the chapter by M. Couderc in this special issue). Although seropositivity is induced for the doctor, it is performative in the social space, for the volunteer's partners, as well as health security representatives operating on the borders of the United States.

Thus, to give consent means to negotiate with a new identity, both for oneself as well as for others. It is therefore appropriate to anticipate the risk of this identity for one's social life (traveling across borders, exclusion from blood donation). This weighing-up process is also an intimate one, and in this case, the authors find the effects of clinical trials relating to early treatment, which supposes that volunteers assume the status of a patient since they are put under treatment, although there is nothing to impose this on the individual from a medical point of view. ${ }^{7}$ In this special issue, Mathilde Couderc rightfully points out the importance of the role of intermediaries in these long, drawn-out negotiations. This topic has received little attention from researchers despite its importance in the execution of trials. ${ }^{8,9}$

\section{CONSENT AS A TRANSACTION}

As several contributions in this work emphasize, the main motivation expected and evaluated of volunteers in trials at the time of their recruitment is altruism. Their participation should not, at least officially, be based on financial motivation or a morbid interest in risk-taking or a pathological fascination with science. This concern for noncommercialization, which is reflected in French law, radically distinguishes the situation in France a priori from the situation in the United States. In the United States, participation in trials is organized by Contract Research Organisations (CROs) based on a model which has spread to other countries. ${ }^{10}$ What the comparison with the American model brings to the reading of the French model is to ask more seriously the question of the benefit associated with participation in a trial, beyond the altruism generally put forward.

At first glance, the recruitment of volunteers seems to be radically different in France and the United States. In France, volunteers are expected to engage altruistically, whereas in the United States, they are compensated. However, if one tries to think of them in terms of each other, which this special issue allows, and if one does not wish solely to distinguish them but to consider what they have in common, the register of the exchange seems to be a unifying notion. For if on the one hand the exchange is monetarized and on the other it is not, in both cases the authors observe both a reciprocity and a professionalization of volunteering. The recruitment in the Ipergay trial (cf. the chapter of $\mathrm{M}$. Trachman and G. Girard in this special issue) is not an exception to the rule, it appears to be a real recruitment which distinguishes between the fallible and irretrievable gays, altruists, and heroes (see Trachman and Girard's) (We should not fail to emphasize the paradox of a trial which takes into account the problems of specific populations but also raises the specter of the notion of populations at risk, whose limits have been widely denounced because of their inability to 
account for the reasons which give rise to the risk, thereby making risk an essential component.).

The 2 recruitment models of France and America both rely on the analysis by Marcel Mauss. ${ }^{11}$ In this classic essay on the social sciences, Marcel Mauss questions the apparently free nature of the donation and proposes an analysis of the rules of exchange in non-Western societies. He proposes "to do away with the rule of law and interest which makes it mandatory $[. .$.$] to return what has been given,"11 (p. 149). Of$ interest for our discussion is the approach of Marcel Mauss to go beyond an analysis of the forms of exchange limited to a monetized dimension. The rule of the gift for the latterwhich is that the exchange is based on a triple obligation: to give, receive, and return-is not always embodied by a monetary transfer, but also by symbolic assets such as prestige or self-esteem and self-realization, for example. Seen in this way, the recruitment of volunteers for trials (in the United States and France) has at least 1 thing in common: there is no free gift because the altruism that determines the engagement of French volunteers is not synonymous with the absence of any transaction. The motivations of volunteers for vaccine trials conducted by the ANRS (cf. the chapter by O. Fillieule in this special issue) demonstrate this: a fascination for science, political engagement, action based on social solidarity and conviction, etc. The "reward" expected by the volunteers in the trial was also considered and evaluated by the selection committees. This triage was therefore not only based on an evaluation of the biological or psychosocial characteristics of the volunteers but also on an assessment of their ability to present their motivations in the best light in accordance with their rhetorical and editorial skills.

The contribution of Olivier Fillieule to this work shows that the profile of recruits has evolved over time, which indicates a normalization of the epidemic. The volunteer recruitment pool is expanding and diversifying. It includes profiles which were absent from the first cohorts and are more representative of the entire population. This democratization of the epidemic which can be observed in recruitment also reflects an evolution in the symbolic rewards of participation, with participation in AIDS research appearing to be less of a vanguard struggle.

Normalization of the epidemic therefore also signifies that engagement has become routine. What can be said about this movement compared with the over-representation of minorities in the cohorts of professional volunteers in the United States? In this regard, the authors observe (cf. the chapter by M.D. Cottingham et al in this work) that a negative representation of HIV still largely forms the basis for the fears expressed by potential volunteers in clinical trials.

\section{DEFINING THE BASIS AND CONTEXT OF TRUST}

As Melissa Leach and James Fairhead point out in an already old work, ${ }^{12}$ vaccines "generate varying notions of trust in the government; responsibility on the part of the media; scientific impartiality; parental choice; citizens" rights, and appropriate limits on the action of the government and the application of liberal democracy (All the translations cited in the text are by the author. $)^{12}$ " (p. 2). Similar to vaccines, clinical trials are about experiences of the body and health, which are part of social relationships, as well as governance and global policy issues. To identify the issues concerned in the question of the vaccine, Leach and Fairhead propose the notion of anxiety but not in an entirely negative way. In this case, anxiety is a driver for refusal of the vaccine and originates in the assumed ignorance of individuals but also has a positive dimension, where "anxieties, as we consider them, are forms of active reflection that are sometimes manifested in action and engagement (or disengagement) with technology and technocracy. Anxieties can take negative forms - as worry, concern or fear - but also positive formsas desire or striving. ${ }^{12}$ " (p. 39). To avoid the rather classic attribution of ignorance in the analysis of vaccination refusals, they also raise the question of the basis, which gives rise to a lack of understanding among the public or a mistrust toward medical policies or medical professionals (ibid, note 4). Similarly, considering recruitment in the trials and the basis of consent partially involves considering the basis of trust. Trust may be broken, as Mathilde Couderc shows (in this work), when there is inconsistent information combining reassuring words about the absence of any risk of HIV infection connected with participation in a vaccine trial with a guarantee that the recipient will receive a certificate explaining the inducted nature of the seropositivity. In this case, inconsistent information gives rise to doubt.

In addition, in the context of a trial involving a healthy volunteer, as in the context of vaccination discussed by Leach and Fairhead, what is important "is rarely a risk in its strict sense of calculable probabilities, but broader uncertainties and ambiguities ${ }^{12 "}$ (p. 170). The authors point out that trust is not a given and that it is necessary to understand the basis on which trust is built. Trust can be given to an institution or to an individual. It depends on the experiences of people, their history, and is part of an interaction on terms which are constantly renewed. Furthermore, trust in an institution is not in any way an indicator of the trust that an individual may have in a process or another individual.

Having confidence in an institution sponsoring a study on the vaccine does not necessarily mean that the volunteer will have confidence in the fact that other people will see him or her as "false HIV-positive" or that he or she will nevertheless be able to identify a true seropositivity in time, if this occurs, etc.

Induced seropositivity, although biologically attestable, is actually co-constructed. It can cause stigmatization of the trial participant, thereby giving rise to anxiety and sometimes withdrawal from the protocols. These anxieties are not the fault of ignorant medical professionals who are unable to distinguish the presence of the virus from the presence of antibodies. They also reflect the functioning of the international health governance where epidemics (including HIV) can still justify the restriction of freedoms (including the right to travel).

The partnership approach at the heart of the vaccine trials conducted by the ANRS and described in this special issue is likely to be a source of inspiration. However, for this partnership to be effective, it needs to be based on a recognition of the legitimate anxieties of the participants rather than 
on a plan to counter ignorance which is seen as a source of mistrust.

This is the objective of the present special issue, which teaches us who the volunteers are and how they think. It is clear on reading the contributions relating to contrasting examples of HIV trials in the United States and Europe, or from the diachronic point of view described by Olivier Fillieule, that the ethics of consent or the basis of recruitment and engagement cannot be analyzed outside of their broader social context.

\section{SHOULD RECRUITMENT BE ANALYZED OR DEFINED?}

There is a tension in the literature between 2 positions in the social sciences regarding the practice of recruitment. This tension is drawn over a spectrum between a position which is purely analytical and comprehensive and a position which is resolutely engaged in the act of recruitment. Regarding the first position, the analysis of the basis for recruitment can be performed after the fact. Although the "usefulness" of the knowledge produced is not in question (it is for the use of operational staff and remains useful in any case for our knowledge of the social aspects of the epidemic and engagement), the researcher does not conduct the recruitment himself. Regarding the second position, the researchers intend rather to answer the question of the possibility of improving recruitment. Although the communication sciences are emblematic of this position in this work, they are not the only sciences concerned (we are of course thinking of sociology or applied anthropology). There is no question here of identifying the right or the wrong position. Each one has its contextual justifications whose relevance is difficult to judge a priori; the fact remains that the place where these 2 positions meet raises ethical and political questions. First of all, what tools are available in practice to clearly distinguish recruitment (explicit, transparent) from seduction or even transgression? For example, this question was raised during the organization of clinical trials during the Ebola epidemic of 2014. For the favipiravir ${ }^{13}$ and plasma trials, ${ }^{14}$ it was decided, in view of Guinea's historical and political context and the nature of the relations between Guineans and Western participants, not to use the term "experimentation" in communications in order not to fuel already significant concerns and rumors. A whole host of questions which are key to the execution of clinical trials are left unresolved (because not addressed) by maintaining a zone of undeterminacy between the use of adequate terms and transgression, between the spirit and the letter. More broadly, the question that this paradigm raises for the social sciences is that of engagement in an assumed social engineering activity ${ }^{15}$ outside of the comfort zone of criticism.

\section{CONCLUSIONS}

HIV vaccine research is part of a long history of vaccine research which began with the smallpox inoculation practices described since the 18 th $^{8}$ century and which have been proven in Asia, Constantinople, ${ }^{16}$ and precolonial
Africa. ${ }^{17}$ This history has been marked once again by the dazzling development of vaccine research on Ebola, which once again demonstrates the interconnection of social, health, scientific, and industrial issues "in a triangle which unites States, societies and international organisations ${ }^{18 "}$ (p. 428). This is what this special issue hopes to achieve, ie, the joint production of knowledge in and about trials while insisting on the legitimacy of contextual knowledge and experience. Indeed, the purpose of experimentation does not diminish the significance of its experience. This special issue reminds us how important it is to see the social sciences grasp this topic in all its multiple facets. In France, the ANRS has played a leading role in this regard. However, there is still a need to determine how research protocols can be constructed jointly taking into account, from the outset of their conception, the multiplicity of trajectories that are deployed in trials, or to put it differently, relying on the different contexts that structure the way the social sciences and clinical research think about trials. ${ }^{19}$

Although the contributions in this special issue emphasize the interest in thinking about consent as a long-term aspect of recruitment, such a dynamic could also be pursued through research on what remains of the trials, on their traces. This does not only constitute infrastructure, notes, or various buildings, ${ }^{20}$ but also professional practices and expertise which has been incorporated.

The notion of "partnership" gives rise to the emergence of a "civic science," which is the question at hand. ${ }^{21}$ However, the decisions to include or exclude participants, which is typical of recruitment, raises the question of which citizens are involved in this case, especially when trials are conducted in countries with limited resources. What would actually happen if nation states were to disappear and be replaced by international organizations or institutions? This question concerns the nature of the interaction between patients and researchers. As Melissa Graboyes reminds us in her discussion of the history of clinical trials in East Africa, "there is a key element that makes this label problematic: there is a very real "therapeutic" dimension to many East Africans" participation in a medical experiment. The lack of a functioning health care system, the poverty, the high rates of preventable yet deadly diseases all mean that the meagre benefits given by Western researchers to offset the risks of participation in research add up to a very real therapeutic benefit." (p. 106). As such, the misunderstanding in this case does not concern the therapeutic aspect, which in reality is clear to everyone, but perhaps the understanding of the social responsibility induced by participation in the trial since the State is largely absent from it. If we wish to preserve the citizenship metaphor, we would have to speak of a form of mobile citizenship ${ }^{22}$ to insist on the temporary and transnational nature of this hybrid form of citizenship.

To understand the multiple voices which contribute to the structure of trials involves a better understanding of the partnership that exists between researchers and volunteers in trials. The ANRS has desired such a partnership since the beginning of the first HIV vaccine trials (cf. the chapter by A. Giami and F. Linard in this special issue). At a time when the recruitment of volunteers continues to be necessary for HIV 
trials, but the disease is losing visibility to the benefit of other causes, the importance of recruitment is even more critical.

\section{REFERENCES}

1. Callon M. Éléments pour une sociologie de la traduction. La domestication des coquilles Saint-Jacques et des marins-pêcheurs dans la baie de Saint-Brieuc. L'Année Sociologique. 1986;36:169-208.

2. Brives C. L'individu dans un essai thérapeutique: Sur quelques aspects du devenir objet dans les expérimentations scientifiques. Revue d'anthropologie des connaissances. 2012;6:653-675. doi:10.3917/rac.017.0185.

3. Bowker GC, Star SL. Sorting Things Out, Classification and its Consequences. Cambridge: The MIT Press; 2000.

4. Scott JC. Domination and the Arts of Resistance: Hidden Transcripts. New Haven, CT: Yale University Press; 1990.

5. Fassin D. Les économies morales revisitées. Ann HSS. 2009;6:12371266.

6. Sariola S, Simpson B. Theorising the human subject in biomedical research: international clinical trials and bioethics discourses in contemporary Sri Lanka. Soc Sci Med. 2011;73:515-521.

7. Brives $\mathrm{C}$, Le Marcis $\mathrm{F}$. Réimaginer des communautés ? Le traitement précoce contre le VIH/sida en Côte d'Ivoire. Terrain. 2015;65:84-103.

8. Kingori P. Experiencing everyday ethics in context: frontline data collectors perspectives and practices of bioethics. Soc Sci Med. 2013; 98:361-370.

9. Graboyes M. The Experiment Must Continue. Medical Research and Ethics in East Africa, 1940-2014. Athens, Greece: Ohio University Press; 2015.

10. Petryna A. When Experiments Travel: Clinical Trials and the Global Search for Human Subjects. Princeton, NJ: Princeton University Press; 2009.

11. Mauss M. Essai sur le don, du don et de l'obligation à rendre. In: Sociologie et anthropologie. Paris, France: PUF; 1950:142-279. (1re éd., 1923-1924, Année sociologique, seconde série).
12. Leach M, Fairhead J. Vaccine Anxieties: Global Science, Child Health and Society. London, United Kingdom: Earthcan; 2007.

13. Sissoko D, Laouenan C, Folkesson E, et al. Experimental treatment with Favipiravir for Ebola virus disease (the JIKI Trial): a historically controlled, single-arm proof- of-concept trial in Guinea. Plos Med. 2016;13:e1001967.

14. Van Griensven J, Edwards T, de Lamballerie X, et al. Evaluation of convalescent plasma for Ebola virus disease in Guinea. $N$ Engl J Med. 2016;374:33-42.

15. Meillassoux C, Messiant C. Génie social et manipulations culturelles en Afrique du Sud. Paris, France: Arcantière Éditions; 1991:312.

16. Moulin AM. La métaphore vaccine. De l'inoculation à la vaccinologie. Hist Philos Life Sci. 1992;14:271-297.

17. Hayden CE. Of Medicine and Statecraft: Smallpox and Early Colonial Vaccination in French West Africa (Senegal-Guinea). A Dissertation Submitted to the Graduate School In Partial Fulfillent of the Requirements For the Degree Doctor Of Philosophy, Field of History. Evanston, IL: Northwestern University; 2008:444.

18. Moulin AM. L'État moderne et les sociétés. Med Sci (Paris). 2007;23: 428-434.

19. Brives C, Le Marcis F, Emilia Sanabria E. What's in a Context? Tenses and Tensions in Evidence-Based Medicine. Medical Anthropology. The Politics and Practices of Evidence in Global Health. London, United Kingdom: Taylor and Francis (Routledge), 2016;35: 369-376.

20. Geissler PW, Lachenal G, Manton J, et al, eds. Traces of the Future. An Archeology of Medical Science in Africa. Bristol, United Kingdom: Intellect-Chicago: Chicago University Press; 2016.

21. Epstein S. Inclusion, the Politics of Difference in Medical Research Chicago, IL: The University of Chicago Press; 2007.

22. Pandolfi M. Moral entrepreneurs, souverainetés mouvantes et barbelés: le bio-politique dans les Balkans postcommunistes. Anthropologie et Sociétés. 2002;26:29-51. 